\title{
EFFECT OF PHYSICO-CHEMICAL PARAMETERS OF WATER CONTAINING LEECH IN UNIVERSITY OF PORT HARCOURT COMMUNITY ABUJA, PORT HARCOURT
}

G. N. WOKE AND N. C. EZE

(Received 3 December 2012; Revision Accepted 22 July 2014)

\begin{abstract}
The physic-chemical parameters of water samples containing leech from the University of Port Harcourt, Abuja Community were examined, between July - September, 2012. The major findings of the results showed that at a low temperature of $21^{\circ} \mathrm{C}$ the $\mathrm{pH}$ was $4.4-4.58$ a high increase in BOD, $2.60-17.8$, COD $12.00-140 \mathrm{mg}$, DO $2.4-80 \mathrm{mg}$ and TSS $20-940$. The results indicated that 28 taxa of the leeches were recorded in 4 families, 5 were recorded in station 1, 2(3); 3(9) and 4(11) Haementeria costata were more in number with a mean density of $3.3 \mathrm{~m}^{2}$ while Erobdella octoculata has the least with a mean density of $0.75 \mathrm{~m}^{2}$. It was observed the leeches were easily adapted to the various ecological conditions due to human activities and the resident fishes in the water body.
\end{abstract}

KEYWORD: Water body, invertebrates, leeches, conductivity and community.

\section{INTRODUCTION}

Leeches are carnivorous invertebrates in the class Hirudinea. A few specific leeches feed on blood. Blood sucking leeches have been used in medical treatment for thousands of years and they continue to be used in certain circumstances today (Kellog, 1994). Humans also encounter leeches in the wild, where they are irritating but not usually harmful (Bartonek and Tranger, 2003).

These animals are called annelids, which means that their bodies are divided into segments. When a leech is viewed under a microscope, the sediments can be clearly seen. Leeches are also hermaphroditic, like many invertebrates. They tend to be aquatic, living in freshwater, swamps, and marshes. Some leeches are also comfortable on land, especially in humid areas like jungles (Davies and Wilkialis, 2001).

Many leeches are carnivorous, feeding on smaller invertebrates. Others scavenge for various organic materials while some leeches attach themselves parasitically to other animals to feed on their blood. Leeches feed on fish, reptities, waterfowl, amphibians, and mammals, depending on the available sources of potential food in their areas. Blood sucking leeches, secrete special chemicals which open blood vessels, inhibit clotting and numb the wound so that their hosts are not aware of their presence until they are already gone (Klemm, 2010).

The physiso-chemical parameters that affect the distribution of leeches has been studied by several workers. For example, some studies have been carried out to examine leech distribution in relation to hardness, total alkalinity and $\mathrm{pH}$. Mann, (2010) showed that alkalinity affects the distribution of leeches, while others have concluded that it does not. However, most species of leeches appear to be most abundant when the total alkalinity $\left(\mathrm{CaCO}_{2}\right)$ exceeds $60 \mathrm{mg} / \mathrm{L}$ with a $\mathrm{pH} 7 / 7.0$. Alkalinity and $\mathrm{pH}$ values within the range $18 \mathrm{mg} / \mathrm{L} \mathrm{-}$ $160 \mathrm{mg} / \mathrm{L}$ and $\mathrm{pH} 7.0-6.0$ probably have the abundance of their prey. This will therefore have an indirect effect on the occurrence and abundance of leeches. Some species have been found at $\mathrm{pH}$ values as low as 4.0 (Mann, 2010).

Leeches are reported to tolerate wide range of water temperature up to an upper limit of $30^{\circ} \mathrm{C}$. Variations in temperature have an important influence on the growth rates and reproductive periods of leeches.

Previous studies on leeches have been carry out especially in the advanced countries of the world where their medicinal importance has been long recognized and put into practice. Consequently many genera and species of different families have been encountered and described. This is true in countries where leech studies have reached advanced stages, for example in Europe and North America, many genera and species of leeches have been described (Sawyer, 2002).

Although leeches are known to occur in Nigeria it would seem that its study has not attracted much attention, like other parasitic organisms. Nevertheless, conducive conditions exists in Nigeria for leeches to thrive in large numbers. Therefore, there seems to be an urgent need for proper studies and documentation of leeches in different parts of Nigeria, such records are largely lacking.

The aim of this study is to ascertain the effect of physico-chemical parameters of water containing leech at University of Port Harcourt community, Abuja Campus.

G. N. Woke, Department of Animal and Environmental Biology, Faculty of Science, University of Port Harcourt, Port Harcourt, Nigeria.

N. C. Eze, Department of Animal and Environmental Biology, Faculty of Science, University of Port Harcourt, Port Harcourt, Nigeria. 


\section{MATERIALS AND METHODS}

The sampling sites were selected from different parts of University of Port Harcourt community. The selection was based on the presence of certain conditions which were considered favourable to leech ecology. These includes the presence of water in form of stream and pool while stagnant water trees are to provide shade in areas that show less of human and industrial activities. A typical sampling sites were fresh water swamp in a virgin forest that has not been cultivated for several years. A total of 4 sites were selected from different parts of University of Port Harcourt community.

Leeches were observed in the laboratory using a binocular microscope. The taxonomic feature used for the identification were based on the work of Elliot and Mann (2004).

\section{Collection of Water Samples}

Water samples were collected from each sample sites. At least 1 litre of water was collected from each site and was placed in 1 litre (1 litre) plastic bottle and returned to the laboratory for physico-chemical analysis. Prior to the collection of the water, the temperature, $\mathrm{pH}$ conductivity were measured in situ, using the appropriate metres, the collected water samples were used in determination of (dissolved oxygen), salinity, biochemical oxygen, demand, TDS (Total Dissolved Oxygen), COD (Chemical Oxygen Demand) and TSS (Total Suspended Solid).

\section{RESULTS}

The results of the selected physico-chemical parameters of the fresh water bodies and leech samples are represented in Table 1 and 2. Physico-chemical parameters determined during the three (3) months, July - September, 2012 sampling periods at four sampling station $(1-4)$ of the University of Port Harcourt community showed that water temperatures ranged from $21.20^{\circ} \mathrm{C}$ to $23.15^{\circ} \mathrm{C}$, fluctuation in water temperatures occurred due to seasonal changes. The $\mathrm{pH}$ of the fresh water ranged from 4.40 to 4.58 (Table 1). Dissolved oxygen, biochemical oxygen demand and chemical oxygen demand increases as follows: DO $(2.40-$ $8.00 \mathrm{mg} / \mathrm{L})$, BOD $(2.60-17.8 \mathrm{mg} / \mathrm{L})$, and COD (12.00 $140 \mathrm{mg} / \mathrm{L})$ while TSS, TDS, Salinity (\%o) and conductivity ranged as follows: TSS $(20-940 \mathrm{mg} / \mathrm{L})$, TDS (20 $40 \mathrm{mg} / \mathrm{L})$, salinity $(14-44-3610 \%)$ and conductivity (19 $-26 \mathrm{Ns} / \mathrm{cm}$ ) (Table 1). The valves for DO were generally high in the rainy season.

Table 1: Selected physico-chemical parameters of the fresh water body

\begin{tabular}{lllll}
\hline Samples/Stations & $\mathbf{1}$ & $\mathbf{2}$ & $\mathbf{3}$ & $\mathbf{4}$ \\
\hline Temperature $\left({ }^{0} \mathrm{C}\right)$ & 22.0 & 21.20 & 21.20 & 23.15 \\
$\mathrm{pH}$ & 4.49 & 4.40 & 4.56 & 4.58 \\
$\mathrm{DO}\left(\mathrm{mg} / \mathrm{L}^{-1}\right)$ & 2.40 & 4.00 & 8.00 & 4.20 \\
$\mathrm{BOD}\left(\mathrm{mg} / \mathrm{L}^{-1}\right)$ & 17.6 & 17.6 & 2.60 & 17.8 \\
$\mathrm{COD}\left(\mathrm{mg} / \mathrm{L}^{-1}\right)$ & 190.0 & 120.0 & 12.00 & 12.00 \\
TSS $\left(\mathrm{mg} / \mathrm{L}^{-1}\right)$ & 940.0 & 20.0 & 20.0 & 23.0 \\
TDS $\left(\mathrm{mg} / \mathrm{L}^{-1}\right)$ & 40.0 & 20.0 & 20.0 & 20.0 \\
Salinity $(\%)$ & 14.44 & 14.44 & 36.10 & 14.44 \\
Conductivity $(\mathrm{Ns} / \mathrm{cm})$ & 26.0 & 20.0 & 19.0 & 20.0 \\
\hline
\end{tabular}

The results of the leeches showed that 4 different species of leeches were recorded from the sampling stations. They belong to the family Glossiphonidae, Haementeria costata, family Hiridindae, Haemopis sanguisunga and Hirudo medicinalis while the family of Erpobdellidae has Erpobdella octoculata as a taxa. A total of 28 taxa leeches were recorded from the University of Port Harcourt community. Out of this number, station 1 had (5), 2(3), 3(9) and 4(11) (Table 2). The major taxa were Haementeria costata while Erpobdella octoculata was the least taxa recorded (Table

Table 2: Composition and abundance of leeches of Uniport community.

\begin{tabular}{llllll}
\hline Species identified & \multicolumn{7}{l}{ Abundance per station } & & \\
\cline { 2 - 7 } & $\mathbf{1}$ & $\mathbf{2}$ & $\mathbf{3}$ & $\mathbf{4}$ & Mean \\
\hline Haementeria costata & 2 & 1 & 4 & 6 & 3.3 \\
Haemopis sanguisuaga & 1 & 1 & 2 & 3 & 1.8 \\
Hirudo medicinalis & 1 & 1 & 2 & 1 & 1.3 \\
Erpobdella octocutata & 1 & - & 1 & 1 & 0.75 \\
Total & $\mathbf{5}$ & $\mathbf{3}$ & $\mathbf{9}$ & $\mathbf{1 1}$ & \\
\hline
\end{tabular}

Also the distribution of leeches in the various stations are shown in Figure 1.1 while Figure 1.2 shows the mean density of the various species occurring in the stations. 


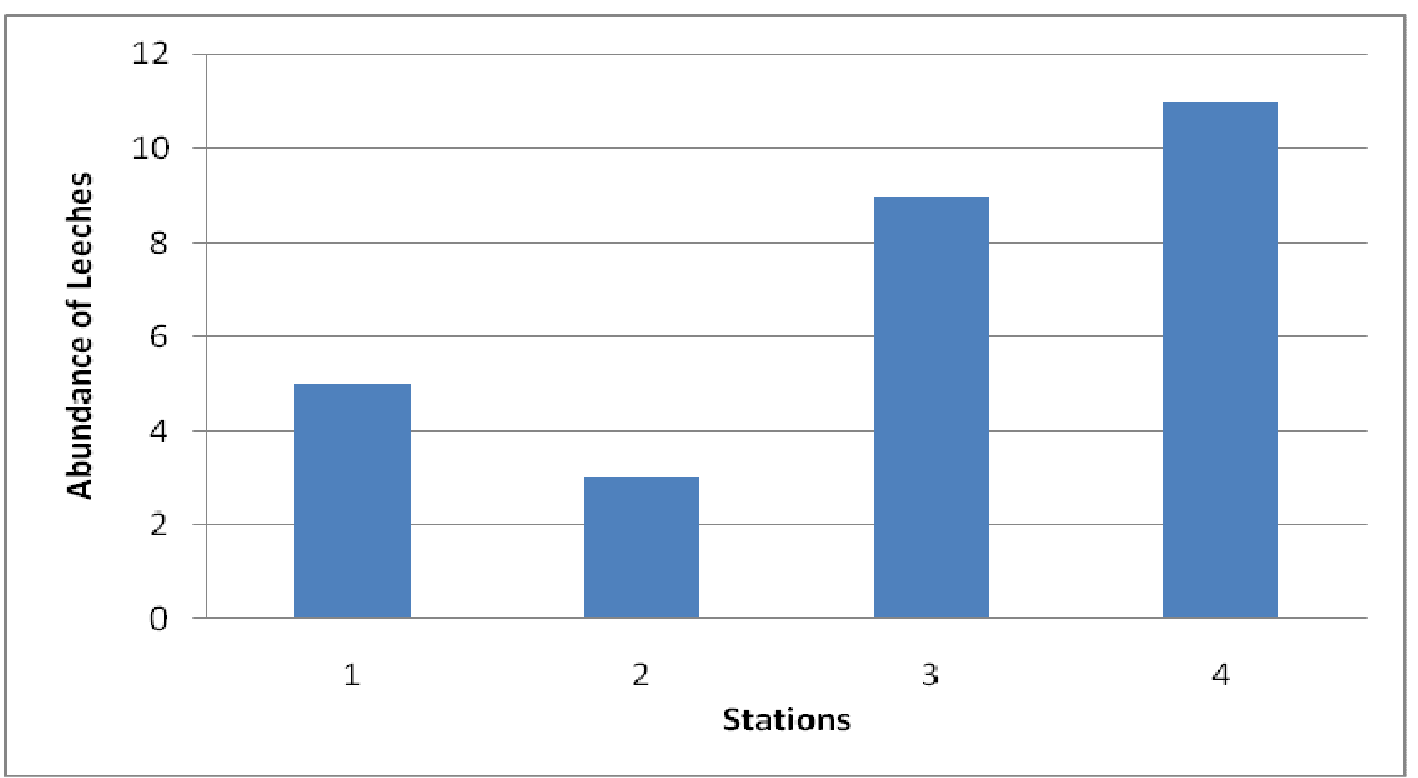

Fig. 1.1: Distribution of leeches in the various stations.

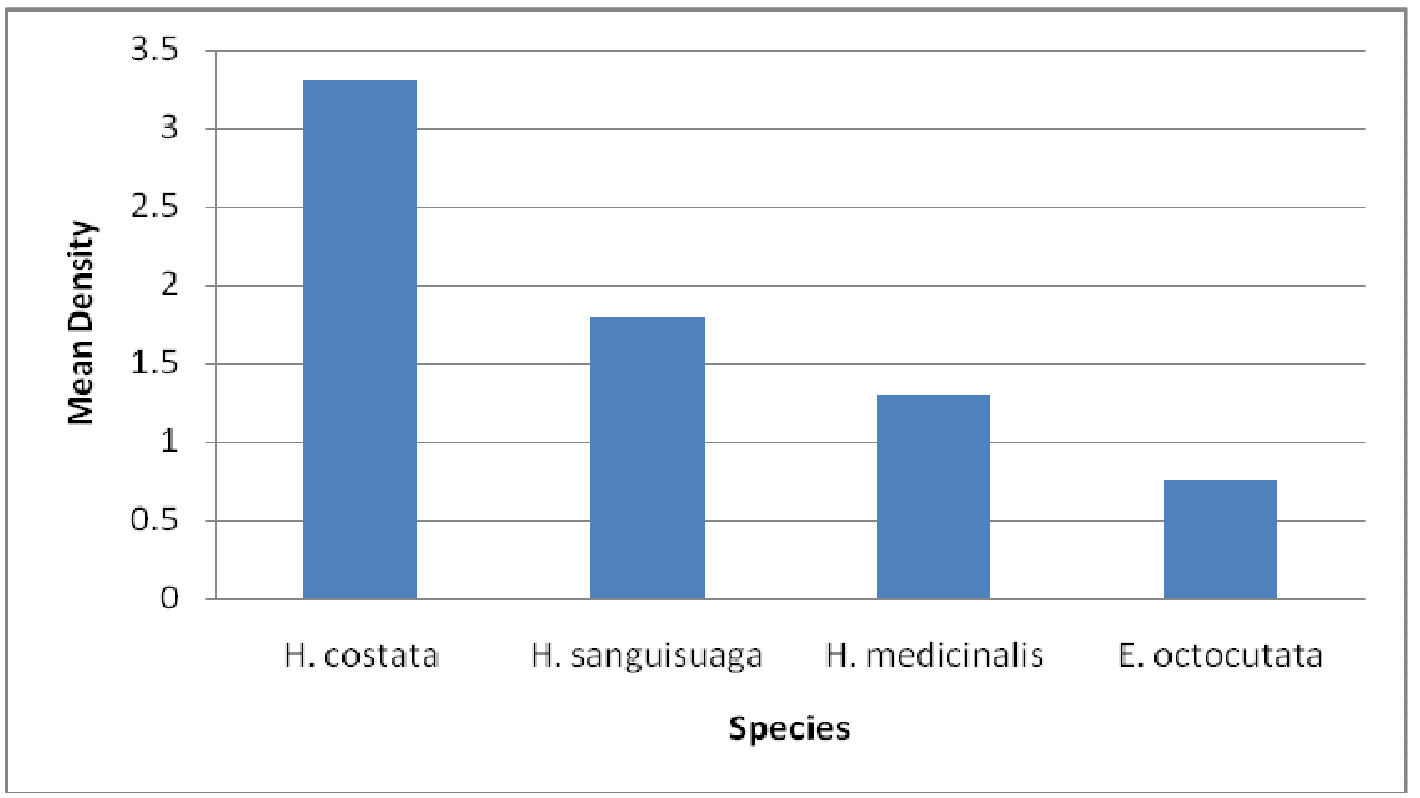

Fig. 1.2: Mean density of the various species in the stations

\section{DISCUSSION}

The fall in oxygen concentration may have been caused by the rise in temperature due to depressed rainfall and the increase in organic load in the water body with corresponding increase in BOD, COD, TSS and TDS (Station 1). Odokuma and Okpokwasili (1996) had observed that the frequent precipitation is a characteristics of the Niger Delta with a long rainy reason from March to October followed by a short spell of dry season referred to as the August break. They indicated that the higher BOD recorded was as a consequence of additional organic matter introduced into the river from surface run-off and soil erosion during the seasonal fluctuation.

High concentration of TDS and TSS in water environment were known to be toxic to aquatic taxa. The temperature and high illumination from the sum within the ecosystem were conductive for all year round marine crop production. The release of conductivity modified the $\mathrm{pH}$ of both the water and leeches towards neutrality, while the release of salinity buffered the same especially the activities of these two parameters.

The four (4) different species of leeches recorded in the study area is due to the ecological conditions which imply that they probably tolerate the same or similar ecological factors. The four species of leeches recorded from the University Community in the present study have been previously recorded in temperate climates were the ecological factors support leech populations in those areas which may be similar to those activities existing in the sampling stations of the Uniport community.

The number of leeches recorded from each sampling station varied from station to station. Although there was variation, but it does not show much 
significant changes, for examples, 5 leeches were recorded in station 1, 2(3), 3(9) and 4(11) etc. This variation would normally suggest the differences in ecological factors; but the results obtained for the physico-chemical studies do not suggest such differences in the water quality. Also leeches that have access to vertebrate host in the water would normally take more blood meals than those that have less access to vertebrate hosts. It is also possible that more leeches could be recorded from waters where human activities such as swimming, washing etc. take place. These are activities that bring the human host into contact with the leeches. Leeches also feed on aquatic animals, for example, the $E$. octoculata recorded in station 1, 2 and 3 has been reported to be carnivorous, tertouring feeding on chironomid larvae, oilgochaetes, ostracods, copepods, and cladocerans among others (Elliot and Mann, 2004). If indeed leeches feed on zooplankton as reported above, it is then understandable, the reasons for their different ecological setting.

Similarities in the ecological situation would mean similarities in the food content of the environments. This would also mean that the same type of leeches were available in the water bodies. This explains why the four species of leeches were recorded in the different sample stations. The absence of leeches in station 2, may be a chance event. It is possible that sampling time and method may have affected the recovery of leeches from the station.

Elliot and Mann (2004) reported that some leeches show endogenous rhythm of activity controlled by change in light intensity, therefore inability to recover leeches in station 2 may be due to collection of sample at the time of low rhythm. It is likely that leeches prefer shaded environment as sample sites, such shaded areas would reduce the intensity of light and perhaps increase the population of the leeches.

The report that fishes feed on leech (Elliot and Mann, 2004) could also mean that leech populations would decrease in waters where such predaceous fishes are found. Most of the waters samples for leeches were known to support fish life, predation by fish may have further reduced fish population in the stations.

\section{CONCLUSION}

In conclusion, it is pertinent to suggest that leeches are easily adaptable to various ecological situations. This has made it possible for the four species of leeches found in temperate water to be recorded in tropical environment of Nigeria. There is need to sample more water bodies in other parts of Nigeria to identify other leech species in the country. This will enhance more accurate and detailed documentation of leeches in Nigeria.

\section{REFERENCES}

Bartonek, J. C and Tranger, D. C., 2003. Leech (Hirudirea) Infestations among water fowl Can. Field Nat. 89, 234-243.

Davies, R. W and Wilkialis, J., 2001. A preliminary investigation on the effect of parasitism of domestic ducklings by Theromyzon rude Canadian J. Zoology 59, 1196-1199.

Elliot, J. M and Mann, K. H., 2004. A key to the British fresh water leeches with notes on their life cycle and ecology scientific publication of the fresh water Biological Association No. 40.

Kellog, L. L., 1994. Save our streams monitors guide to Aquatic macro-invertebrates Izaak Walton League of America 60pp.

Klemm, D. J., 2010. Studies on the feeding relations of leeches (Amelida Hirudinea) as natural associates of mollusks Skerkiana 58, 1-50: 89, $1-20$.

Mann, K. H., 2010. A revision of the British leeches of family Glossiphoniidae with a description of Batracobdella palaudosa, a leech new to British fauna Proc. Zool. Soc. London 123, 377-391.

Mann, K. H., 2010. Seasonal variation in the respiratory acclimatization of the leech Erpodbella testacecea.

Odokuma, L. O and Okpokwasili, G. C., 1996. Seasonal influence of the organic pollution monitoring of New Calabar River, Nigeria. Enviro. Mon. and Assess. 45: 43-56.

Sawyer, R. T., 2002. Leech Biology and Behaviour. Vol. 11. Feeding, Biology, Ecology and Systematics $167 p p$. 